\title{
Management of arteriovenous malformations in the elderly: a single-center case series and analysis of outcomes
}

\author{
Aqueel H. Pabaney, MD, Kevin A. Reinard, MD, Max K. Kole, MD, Donald M. Seyfried, MD, and \\ Ghaus M. Malik, MD
}

Department of Neurological Surgery, Henry Ford Hospital, Detroit, Michigan

\begin{abstract}
OBJECTIVE Treatment of brain arteriovenous malformations (bAVMs) in the elderly remains a challenge for cerebrovascular surgeons. In this study the authors reviewed the patient characteristics, treatments, angiographic results, and clinical outcomes in 28 patients over 65 years of age who were treated at Henry Ford Hospital between 1990 and 2014.

METHODS The bAVM database at the authors' institution was queried for records of elderly patients with bAVMs, and data regarding patient demographics, presenting symptoms, bAVM angioarchitecture, treatment modalities, angiographic results, clinical outcomes, and treatment complications were tabulated and analyzed.

RESULTS There were 9 male (32\%) and 19 female (68\%) patients, with an average age ( \pm SD) of $73.0 \pm 6.95$ years. The most common symptoms on presentation were hemorrhage $(36 \%)$ and headaches $(18 \%)$. The bAVMs were equally distributed between the supra- and infratentorial compartments. The most common Spetzler-Martin grade was II, observed in $57 \%$ of the patients. Eleven patients (39.3\%) underwent resection, 4 patients $(14.3 \%)$ received standalone radiation therapy, and 13 patients $(46 \%)$ did not receive treatment or were managed expectantly. Four patients $(14.3 \%)$ were lost to follow-up. Complete bAVM obliteration was achieved in $87 \%$ of the treated patients. None of the patients who received any form of treatment died; the overall mortality rate was $3.6 \%$.
\end{abstract}

CONCLUSIONS Surgical management of bAVMs in the elderly can result in complete obliteration and acceptable clinical outcomes.

http://thejns.org/doi/abs/10.3171/2015.6.JNS15293

KEY WORDS arteriovenous malformation; elderly; microsurgery; stereotactic radiosurgery; vascular disorders

$\Lambda$ RTERIOVENOUS malformations (AVMs) are congenital vascular lesions with an incidence of $1-1.14$ cases per 100,000 persons and an annual rate of hemorrhage around $2 \%-4 \%$ in untreated patients. ${ }^{1,11}$ While female sex, subcortical location, prior rupture history, deep venous drainage, and association with intracranial aneurysms have previously been identified as risk factors that could increase the risk of hemorrhage, ${ }^{2}$ a recent meta-analysis showed that every 10 additional years in patient age correlates with an approximately $30 \%$ increase in the risk of AVM rupture. ${ }^{16}$ Additionally, while longitudinal population-based studies have demonstrated that most brain AVMs (bAVMs) become symptomatic in the fourth and fifth decade of life and may, consequently, be infrequently encountered in the elderly population, ${ }^{22}$ conflicting reports suggest that the course of bAVMs in the elderly is not be- nign and that a preponderance of bAVMs in this age group present with hemorrhage. , $^{8,12}$

While the natural history of bAVMs is widely described, only a limited number of reports have exclusively focused on the natural history and management of bAVMs in the elderly population. ${ }^{12,13,17}$ Because of this, and as a result of the absence of consensus guidelines for the management of bAVMs in the elderly population, treatment of these complex vascular lesions in the elderly will continue to challenge cerebrovascular surgeons, especially in light of the ubiquity of diagnostic brain imaging tools ${ }^{10}$ and a concomitant rise in global life expectancy. ${ }^{19,25}$

With remarkable advances in endovascular technology, radiation therapy, as well as microsurgical techniques, multimodality management of bAVMs has proven effective and safe across various age groups. ${ }^{4,9,23}$ However, the

ABBREVIATIONS ARUBA = A Randomized trial of Unruptured Brain AVMs; AVM = arteriovenous malformation; bAVM = brain AVM; ICH = intracerebral hemorrhage; $m$ RS $=$ modified Rankin Scale; SCA = superior cerebellar artery; SM = Spetzler-Martin; SRS = stereotactic radiosurgery.

SUBMITTED February 6, 2015. ACCEPTED June 4, 2015.

INCLUDE WHEN CITING Published online November 20, 2015; DOI: 10.3171/2015.6.JNS15293. 
recent publication of the first randomized trial of unruptured AVMs (A Randomized trial of Unruptured Brain AVMs [ARUBA]) has generated controversy in regards to the optimal treatment strategy for bAVMs. ${ }^{20}$ We sought to determine the ideal treatment strategy for elderly patients harboring bAVMs by reviewing our experience with bAVMs in the elderly population.

\section{Methods \\ Data Collection}

In accordance with the Henry Ford Institutional Review Board, we queried our bAVM database from 1990 to 2014 to identify 28 elderly patients with pial bAVMs. The accepted, minimum cutoff age of 65 years for "elderly" was applied to all patients. ${ }^{21}$ Patients harboring vascular malformations other than pial bAVMs (arteriovenous fistulas, cavernous malformations) were excluded. Electronic medical records were searched to gather patient demographic data including age, sex, presence of hypertension, and symptoms upon presentation. Clinical information regarding presence or absence of intracerebral hemorrhage (ICH) on CT scans, flow-related aneurysms, and treatment options employed (preoperative embolization, microsurgery, and stereotactic radiosurgery [SRS]) were also gathered. A Spetzler-Martin (SM) grade was given to all patients to assess surgical risk. ${ }^{24}$ All patients received 6-vessel cerebral angiography to assess bAVM obliteration status after treatment. Medical records were carefully screened to assess patient functional outcomes prior to treatment and later in the follow-up period. A modified Rankin scale (mRS) score was assigned to each patient. Patients who were lost to follow-up were excluded from the statistical analysis because their final outcomes were unknown.

\section{Statistical Analysis}

For statistical analyses, the patients were grouped on the basis of the presence or absence of hemorrhage on presentation as well as on the basis of intervention (treated vs untreated). We used an independent, 2-tailed t-test (Welch generalization of the Student t-test, Microsoft Excel 2013) to compare patient age; SM grade; mean mRS score at the time of presentation and at last follow-up between treated and observed groups, as well as between ruptured and unruptured cohorts; and average duration of followup. The Fisher exact test was used to compare patient sex, rupture status, bAVM nidus location, and functional status between the groups. A p value of $<0.05$ was accepted for statistical significance.

\section{Results \\ Patient Characteristics}

Our institutional query identified 28 patients over the age of 65 with pial bAVMs who received care at Henry Ford Hospital between 1990 and 2014 (Table 1). The average age $( \pm \mathrm{SD})$ of the patient cohort at presentation was $73.0 \pm 6.95$ years. No statistically significant difference was detected between the age of patients presenting with or without hemorrhage $(\mathrm{p}=0.416)$. There were 19 female (68\%) and 9 male (32\%) patients. Sixteen patients (57\%) carried a diagnosis of chronic hypertension at presenta- tion. The most common presenting symptom was hemorrhage, which was observed in 10 patients (36\%) followed by headaches (18\%). A bAVM was discovered incidentally in 4 patients $(14.3 \%)$. Seizures were the presenting manifestation in only 2 patients (7\%). The bAVMs were equally distributed between the supratentorial and infratentorial compartments (50\% each). Supratentorial bAVMs were located largely in the temporal and parietooccipital lobes (21\%); of the infratentorial bAVMs, 6 (21\%) were vermian and $4(14 \%)$ involved the cerebellar hemispheres. The vascular malformations were classified as SM Grade I in 2 patients (7.1\%), SM Grade II in 16 patients (57.1\%), SM Grade III in 8 patients (28.6\%), SM Grade IV in 1 patient (3.6\%), and SM Grade V in 1 patient (3.6\%). There was no statistically significant difference between the mean SM grade of the patient cohort presenting with or without hemorrhage $(\mathrm{p}=0.973)$. Chronic hypertension was not found to be a potential risk factor for bAVM rupture in this population (odds ratio 0.63, 95\% confidence interval 0.13-3.02). Five patients (18\%) harbored flow-related aneurysms. Another 3 patients (11\%) harbored concurrent vascular anomalies ( 2 nonfeeding artery aneurysms and 1 dural arteriovenous fistula). Only 1 of 8 patients with a concomitant vascular pathology presented with a ruptured bAVM.

\section{Treatment Versus Observation}

All patients were presented at our multidisciplinary bAVM board that consists of cerebrovascular and endovascular neurosurgeons, interventional neuroradiologists, as well as radiation oncologists, before a patient-centered treatment plan was conceived and offered to each patient. The recommended treatment was undertaken if the board rendered a consensus opinion that complete bAVM obliteration was feasible with minimal risk to the patient; no treatment was undertaken if the patient declined intervention or if any treatment carried an unfavorable risk-benefit profile. Generally, at our institution, we offer intervention to all patients who are healthy, harbor SM Grade I, II, or III lesions, and have a life expectancy of 5 years or more. Of the 28 patients in our series, 15 patients $(53.6 \%)$ underwent any kind of treatment: 10 patients $(66.7 \%)$ underwent standalone microsurgical resection, 4 patients (26.7\%) underwent standalone SRS, and only 1 patient (6.6\%) underwent salvage microsurgical resection after SRS failed to obliterate the bAVM. None of the patients underwent preoperative bAVM embolization secondary to unfavorable angioarchitecture (Table 2).

Among the 10 patients with ruptured bAVMs (Table 3), $6(60 \%)$ underwent treatment (resection in 5, SRS in 1). In contrast, of the 18 patients with unruptured bAVMs, $9(50 \%)$ underwent treatment (resection in 5, SRS in 3, SRS followed by resection in 1). The 13 patients (46.4\%) who did not receive any treatment carried an unfavorable risk-benefit profile or declined any form of treatment; $40 \%$ of patients with ruptured bAVMs (4 patients) were not treated because 3 patients declined treatment and 1 patient was poor grade at presentation (mRS score of 5) and died shortly after. Among unruptured bAVMs, 50\% (9 patients) did not undergo any treatment. Four patients declined treatment, 2 patients were lost to follow-up, and our multidisciplinary bAVM board recommended against any 
TABLE 1. Patient demographics, AVM characteristics, treatments, outcomes, and complications

\begin{tabular}{|c|c|c|c|c|c|c|c|c|c|}
\hline \multirow[b]{2}{*}{$\begin{array}{c}\text { Case } \\
\text { No. }\end{array}$} & \multirow[b]{2}{*}{$\begin{array}{c}\text { Age (yrs), } \\
\text { Sex }\end{array}$} & \multirow[b]{2}{*}{ Presentation } & \multirow[b]{2}{*}{ Location } & \multirow[b]{2}{*}{ SM Grade } & \multirow[b]{2}{*}{ Treatment } & \multicolumn{2}{|c|}{ mRS Score } & \multirow[b]{2}{*}{$\begin{array}{l}\text { Follow- } \\
\text { Up (mos) }\end{array}$} & \multirow[b]{2}{*}{ Complications } \\
\hline & & & & & & Presentation & $\begin{array}{c}\text { Last } \\
\text { Follow-Up }\end{array}$ & & \\
\hline 1 & $78, M$ & Seizures & Parietooccipital & III & None & 1 & 1 & 240 & - \\
\hline 2 & $84, F$ & Tinnitus & Vermian & II & None & 1 & 1 & 84 & - \\
\hline 3 & $69, F$ & Dizziness & Cerebellar & $\|$ & None & 1 & 1 & 60 & - \\
\hline 4 & $65, F$ & Headaches & Parietooccipital & IV & None & 1 & NA & Lost & - \\
\hline 5 & $68, F$ & Headaches & Parietal & II & None & 0 & 0 & 84 & - \\
\hline 6 & $87, \mathrm{~F}$ & Syncope & Parietooccipital & III & None & 1 & 1 & 12 & - \\
\hline 7 & $71, \mathrm{~F}$ & Amnesia & Superior cerebellar & II & None & 0 & 0 & 24 & - \\
\hline 8 & $78, F$ & Headaches & Sylvian fissure & II & None & 1 & NA & Lost & - \\
\hline 9 & $68, F$ & Speech arrest & Pineal & $\|$ & None & 1 & 1 & 108 & - \\
\hline 10 & $65, M$ & Incidental & Inferior vermian & $\|$ & Surgery* & 0 & 0 & 72 & - \\
\hline 11 & $77, \mathrm{~F}$ & Incidental & Frontal & II & Surgery* & 0 & 0 & 36 & - \\
\hline 12 & $65, \mathrm{M}$ & Dizziness & Sylvian fissure & III & Surgery* & 1 & 1 & 36 & - \\
\hline 13 & $65, F$ & Seizures & Frontoparietal & II & Surgery* & 1 & 2 & 84 & Hemiparesis \\
\hline 14 & $72, \mathrm{M}$ & Headaches & Vermian & II & Surgery* & 1 & 3 & 15 & Ataxia, seizures \\
\hline 15 & $68, F$ & Headaches & $\mathrm{CP}$ angle & III & SRS, then surgery* & 1 & 1 & 12 & - \\
\hline 16 & $79, \mathrm{M}$ & Speech disturbance & Tectal & III & SRS & 1 & 0 & 12 & - \\
\hline 17 & $73, F$ & Incidental & Superior cerebellar & I & SRS & 0 & 0 & 12 & - \\
\hline 18 & $68, F$ & Incidental & Occipital & III & SRS* & 1 & 1 & 48 & - \\
\hline 19 & $89, \mathrm{M}$ & $\mathrm{ICH}$ & Temporal & II & None & 0 & 0 & 2 & - \\
\hline 20 & $80, F$ & $\mathrm{ICH}$ & Choroidal fissure & II & None & 2 & NA & Lost & - \\
\hline 21 & $70, \mathrm{~F}$ & $\mathrm{ICH}+\mathrm{IVH}$ & Frontoparietal & V & None & 5 & 6 & 0 & Death \\
\hline 22 & $69, \mathrm{M}$ & $\mathrm{ICH}$ & Occipital & II & None & 2 & NA & Lost & - \\
\hline 23 & $70, \mathrm{~F}$ & $\mathrm{ICH}+\mathrm{HCP}$ & Inferior vermian & $\|$ & Surgery* & 3 & 2 & 48 & - \\
\hline 24 & $70, \mathrm{~F}$ & $\mathrm{ICH}$ & Superior Vermian & $\|$ & Surgery* & 1 & 0 & 108 & - \\
\hline 25 & $65, \mathrm{M}$ & $\mathrm{ICH}$ & Superior cerebellar & I & Surgery* & 2 & 3 & 12 & Hemiparesis \\
\hline 26 & $77, \mathrm{M}$ & $\mathrm{ICH}$ & Temporal & II & Surgery* & 2 & 2 & 48 & - \\
\hline 27 & $82, F$ & $\mathrm{IVH}+\mathrm{HCP}$ & Superior vermian & III & Surgery* & 2 & 1 & 10 & \\
\hline 28 & $73, \mathrm{~F}$ & IVH & Fourth ventricle & III & SRS $^{*}$ & 0 & 2 & 24 & Ataxia \\
\hline
\end{tabular}

$\mathrm{CP}=$ cerebellopontine $\mathrm{HCP}=$ hydrocephalus $; \mathrm{IVH}=$ intraventricular hemorrhage; $\mathrm{NA}=$ not applicable.

* AVM was completely obliterated.

treatment for 3 patients because of high SM grade (Grade III or IV) and unacceptably high treatment-associated risks. All patients who underwent microsurgery achieved complete obliteration of their bAVM confirmed by postoperative angiography, whereas 2 patients (40\%) who received SRS attained complete obliteration. One of the patients who underwent SRS treatment elected to undergo surgical excision when a follow-up angiogram performed 4 years after initial treatment failed to show bAVM obliteration.

\section{Outcome Data}

The mean mRS score for the entire cohort was $1.14 \pm$ 1.08 at presentation and increased to $1.21 \pm 1.38$ at the time of the last follow-up evaluation (Table 1). The mean initial mRS score for patients presenting with hemorrhage was significantly worse as compared with patients without hemorrhage (1.9 vs 0.72 , respectively; $\mathrm{p}=0.003$ ). The mean functional outcome of patients with ruptured bAVMs did not deteriorate after receiving any form of treatment (initial and late $\mathrm{mRS}$ score $=1.67$ ). In contrast, the functional status of elderly patients with ruptured bAVMs who did not receive any treatment declined but did not reach statistical significance by the time of the last follow-up (initial $\mathrm{mRS}$ score 2.25 vs late $\mathrm{mRS}$ score 3.0; $\mathrm{p}=0.770)$. Within the unruptured cohort, there was no difference in the mean initial and late mRS score between the treated and untreated patients $(0.67$ vs $0.78, \mathrm{p}=0.620$, and 0.89 vs $0.71, p=0.690$, respectively). Overall, median clinical follow-up duration was 36 months for 24 patients ( $86 \%$ follow-up rate). Median clinical and/or radiological follow-up for patients who did not undergo any treatment was 60 months, whereas median follow-up for patients who underwent any treatment was 36 months.

Of the 15 patients who received treatment, 11 (73\%) remained functionally the same or displayed neurological improvement while 4 patients (27\%) deteriorated functionally (Table 2); there were no deaths among the treated patients. Of the 13 patients who did not receive any treatment, 8 patients $(61.5 \%)$ improved functionally or 
TABLE 2. Comparison of treatment and observation cohorts

\begin{tabular}{|c|c|c|c|}
\hline Characteristic & $\begin{array}{l}\text { Treatment } \\
(n=15)\end{array}$ & $\begin{array}{l}\text { Observation } \\
\quad(n=13)\end{array}$ & $\mathrm{p}$ Value \\
\hline \multicolumn{4}{|l|}{ Sex } \\
\hline Male & 6 & 3 & \multirow[t]{2}{*}{0.33} \\
\hline Female & 9 & 10 & \\
\hline Mean age (yrs) & 71.26 & 75.07 & 0.15 \\
\hline \multicolumn{4}{|l|}{ Presentation } \\
\hline Hemorrhage & 6 & 4 & \multirow{3}{*}{0.61} \\
\hline Headaches & 2 & 3 & \\
\hline Seizures & 1 & 1 & \\
\hline \multicolumn{4}{|l|}{ Location } \\
\hline Supratentorial & 5 & 9 & \multirow[t]{2}{*}{0.06} \\
\hline Infratentorial & 10 & 4 & \\
\hline \multicolumn{4}{|l|}{ SM grade } \\
\hline 1 & 2 & 0 & \multirow{6}{*}{0.39} \\
\hline$\|$ & 7 & 9 & \\
\hline III & 6 & 2 & \\
\hline IV & 0 & 1 & \\
\hline V & 0 & 1 & \\
\hline Mean & 2.27 & 2.53 & \\
\hline \multicolumn{4}{|l|}{ Treatment } \\
\hline Surgery & 10 & - & \\
\hline Endovascular & 0 & - & \\
\hline SRS & 4 & - & \\
\hline Combination & 1 & - & \\
\hline Mean follow-up (mos) & 38.47 & 68.2 & 0.18 \\
\hline \multicolumn{4}{|l|}{ Outcomes (mRS score) } \\
\hline Initial & 1.067 & 1.23 & 0.67 \\
\hline Final & 1.2 & 1.22 & 0.97 \\
\hline \multicolumn{4}{|l|}{ Functional status } \\
\hline Improved/same & 11 & 8 & 0.36 \\
\hline Worse & 4 & 1 & \\
\hline Lost to follow-up & 0 & 4 & \\
\hline
\end{tabular}

remained the same by the last follow-up, 1 patient $(7.7 \%)$ died, and 4 patients (30.8\%) were lost to follow up. Irrespective of the presenting symptomatology, no statistically significant difference was detected in the mean mRS scores of the patients who received any form of treatment as compared with those who did not $(\mathrm{p}=0.36)$. We also dichotomized our patients into two groups: patients with low-grade bAVMs (SM Grades I and II; $n=18$ ) and those with high-grade bAVMs (SM Grades III-V; $\mathrm{n}=10$ ). For the overall cohort, no difference in functional outcome was detected when comparing patients in the low-grade group to those harboring high-grade lesions $(p=0.896)$. Furthermore, no difference was detected in functional outcomes when we compared patients with low-grade lesions who received any treatment to those with high-grade lesions who were treated $(\mathrm{p}=0.47)$.

\section{Illustrative Cases \\ Case 15}

A 68-year-old woman presented to us with an incidental bAVM. The patient's neurological examination was nonfocal. Digital subtraction angiography revealed a 1.5
TABLE 3. Comparison of ruptured and unruptured groups

\begin{tabular}{|c|c|c|c|}
\hline Characteristic & $\begin{array}{c}\text { Ruptured } \\
(n=10)\end{array}$ & $\begin{array}{l}\text { Unruptured } \\
\quad(n=18)\end{array}$ & $\mathrm{p}$ Value \\
\hline \multicolumn{4}{|l|}{ Sex } \\
\hline Male & 4 & 5 & \multirow[t]{2}{*}{0.51} \\
\hline Female & 6 & 13 & \\
\hline Mean age (yrs) & 74.5 & 72.2 & 0.42 \\
\hline Hypertension & 5 & 9 & 0.57 \\
\hline \multicolumn{4}{|l|}{ Location } \\
\hline Supratentorial & 5 & 9 & \multirow[t]{2}{*}{1} \\
\hline Infratentorial & 5 & 9 & \\
\hline SM grade & 2.4 & 2.39 & 0.97 \\
\hline \multicolumn{4}{|l|}{ Treatment } \\
\hline Surgery & 5 & 5 & \multirow{5}{*}{0.61} \\
\hline Endovascular & 0 & 0 & \\
\hline SRS & 1 & 3 & \\
\hline Combination & 0 & 1 & \\
\hline None & 4 & 9 & \\
\hline \multicolumn{4}{|c|}{ Outcomes (mRS score) } \\
\hline Initial & 1.9 & 0.72 & $0.003^{*}$ \\
\hline Final & 2 & 0.81 & $0.044^{*}$ \\
\hline \multicolumn{4}{|l|}{ Functional status } \\
\hline Improved/same & 5 & 14 & 0.155 \\
\hline Worse & 3 & 2 & \\
\hline
\end{tabular}

* Statistically significant $(p<0.05)$.

$\mathrm{cm} \times 2 \mathrm{~cm}$ nidus in the right cerebellar hemisphere abutting the middle cerebellar peduncle with arterial supply from the inferior division of the superior cerebellar artery (SCA), a 5-mm flow-related aneurysm (Fig. 1A), as well as venous drainage through the Galenic system and the superior petrosal sinus (SM Grade III; Fig. 1B). The bAVM board recommended resection, but the patient opted for radiation therapy and underwent SRS (Gamma Knife) at another institution. Serial imaging failed to demonstrate complete bAVM obliteration after 4 years (Fig. 1C). The patient subsequently agreed to undergo resection. Preoperative embolization was attempted, albeit unsuccessfully, due to the inability to catheterize the inferior division of the SCA. The bAVM was resected through a lateral, suboccipital corridor without an attempt to clip the SCA aneurysm. Postoperative angiography revealed complete bAVM resection and persistence of the small, prenidal aneurysm (Fig. 1D). The patient did not suffer any new neurological deficits and continued to do well at her 1-year follow-up visit.

\section{Case 27}

An 82-year-old woman was brought to the emergency department after a syncopal episode at a gas station. On examination, she was stuporous but had no focal neurological deficits. The initial head CT scan revealed ICH in the superior vermis with ventricular extension and associated hydrocephalus (Fig. 2A). An external ventricular drain was placed. Digital subtraction angiography revealed a 2 $\mathrm{cm} \times 1.5 \mathrm{~cm}$ superior vermian bAVM supplied by bilateral SCAs and the left posterior inferior cerebellar artery. Venous drainage was through the posterior mesencephalic 

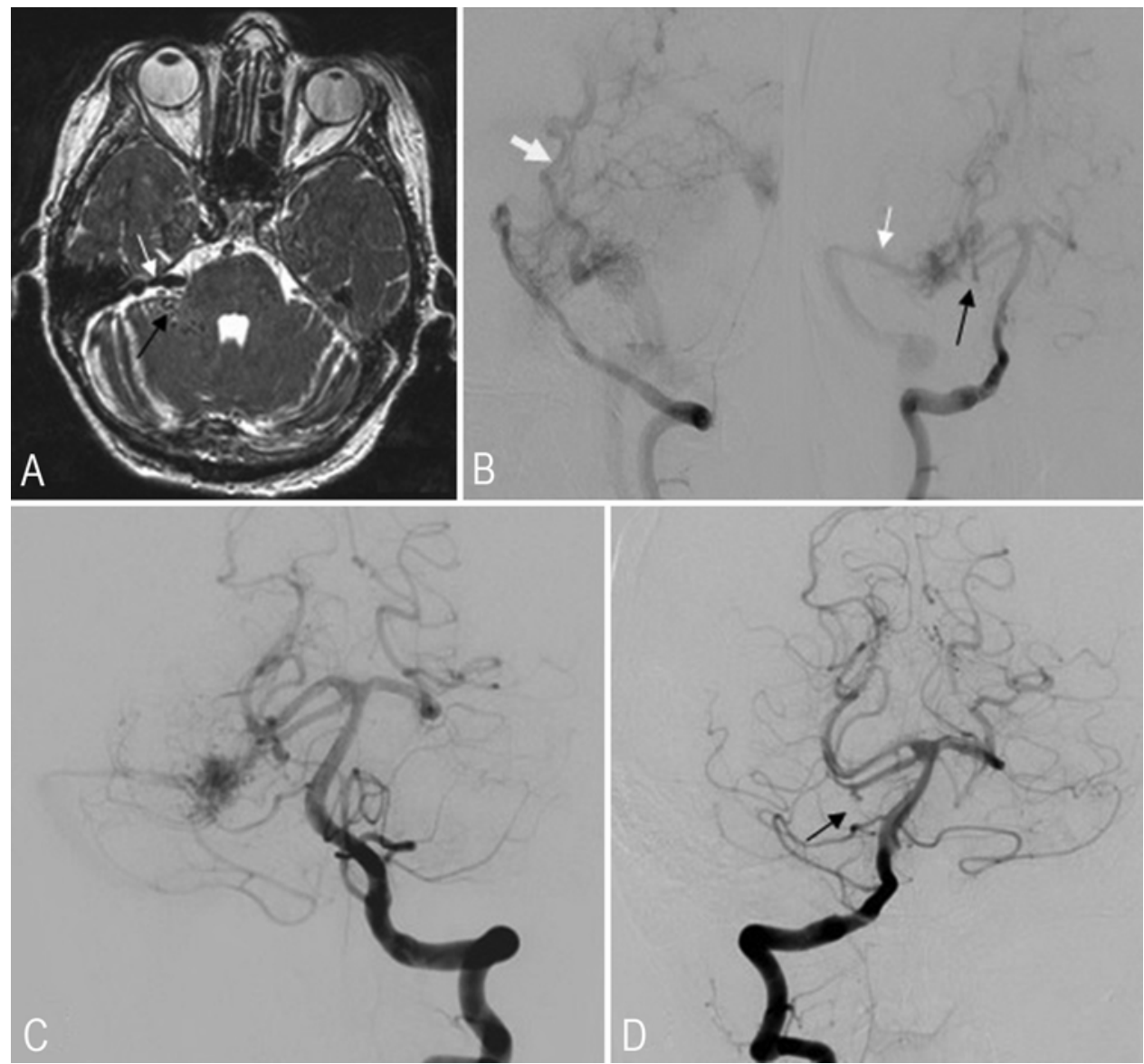

FIG. 1. Case 15. A: Axial T2-weighted MRI shows flow voids in the right cerebellopontine angle (white arrow) and middle cerebellar peduncle (black arrow). B: Right vertebral artery injection angiogram reveals a bAVM being supplied by the right SCA and draining via the posterior mesencephalic vein (thick white arrow) and petrosal sinus (thin white arrow). A feeding artery aneurysm is also appreciated (black arrow). C: Left vertebral artery injection angiogram revealed persistence of a bAVM 4 years after SRS. D: Postoperative angiogram reveals complete obliteration of the bAVM while the aneurysm persists (black arrow).

vein into the vein of Galen (Fig. 2B). With CSF diversion, the patient's neurological status improved, and the external ventricular drain was successfully challenged and discontinued. After a course of rehabilitation, the patient underwent resection through a posterior interhemispheric, transtentorial approach with the patient in a three-quarter prone position. Postoperative angiography revealed complete bAVM resection with no evidence of arteriovenous shunting (Fig. 2C). At her last follow-up evaluation, the patient had recovered well from her surgery and was at her neurological baseline.

\section{Discussion}

Population demographics have significantly changed in the last century. It is expected that by the year 2050 the elderly population will double from 43.1 million to nearly 83.7 million (http://www.census.gov/population/ projections/data/national/2012.html). While elderly patients were traditionally categorized as high-risk surgical candidates, remarkable advances in neuroanesthesia, neuromonitoring, and neurocritical care have afforded neurosurgeons the opportunity to successfully perform complex neurosurgical procedures on the elderly, both on an elective and emergency basis. ${ }^{7}$ A steady rise in the number of complex neurosurgical procedures in the elderly has been accompanied by a decline in complication rates as evidenced by morbidity and mortality rates that are lower than ever before. An analysis of several reports on outcomes after neurosurgical procedures in the elderly has revealed that advanced age can no longer be used as an absolute contraindication to any neurosurgical intervention. ${ }^{7}$

Intracranial bAVMs are uncommon, likely congenital vascular lesions that mostly present with hemorrhage or seizures. With widespread use of imaging technologies, the incidence of bAVMs in the elderly is on the rise. Until recently, elderly patients harboring bAVMs were managed expectantly based on the assumption that intracranial bAVMs in the elderly have a benign natural history because the risk of bleeding significantly diminishes after 40 years of age as compared with bAVMs in younger patients, which are fraught with devastating hemorrhage..$^{14,18}$ Crawford et al., in contrast, noted that the risk of hemorrhage was significantly higher during follow-up for older patients as compared with younger patients in the same time period. ${ }^{8}$ Similarly, Brown and colleagues noted that 

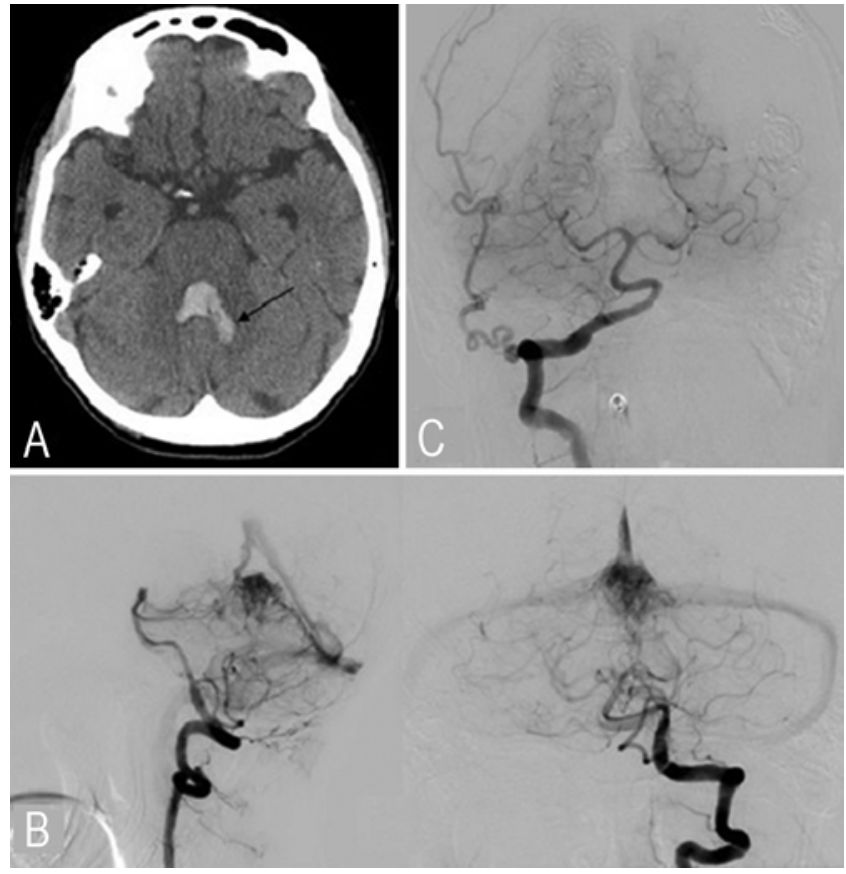

FIG. 2. Case 27. A: Nonenhanced axial CT scan showing blood in the fourth ventricle along with a small component of hematoma adjacent to the vermis (arrow). B: Anteroposterior and lateral projection angiograms of left vertebral artery injection reveal a superior vermian bAVM supplied by bilateral SCAs and draining through the posterior mesencephalic vein. C: Postoperative angiogram reveals complete excision of the bAVM with no arteriovenous shunting.

$20 \%$ of ICHs in elderly patients occurred secondary to intracranial vascular malformation. ${ }^{6}$ Another study, by Hetts et al., proposed that high-risk bAVM features such as venous ectasia and feeding artery aneurysms were more common in the adult population compared with children. They hypothesized that prolonged hemodynamic stress over time could potentiate bAVM rupture in the elderly population. ${ }^{15}$

Our study represents one of the largest cohorts of elderly patients with intracranial bAVMs and features several important lessons. First, the most common mode of bAVM presentation in patients above the age of 65 years was $\mathrm{ICH}$, underscoring the fact that the natural history of bAVMs in the elderly is not benign as once believed and warrants aggressive, multimodal treatment. Given the average life expectancy is 84 and 86 years for males and females, respectively, in the US (http://www.ssa.gov/planners/life expectancy.htm), the likelihood of lifetime hemorrhage in a patient diagnosed with a bAVM at 65 years of age will be $40 \%-80 \%$ and the risk of death or permanent neurological deficit will be $50 \%$, a substantial risk that warrants early treatment. Additionally, a multicenter, individual patientlevel meta-analysis clearly showed that increasing age is an independent predictor of hemorrhage during followup. ${ }^{16}$ Second, two-thirds of our elderly patients harbored SM Grade I or II lesions. Resection is considered the optimal treatment for low-grade bAVMs, ${ }^{5}$ a fact corroborated by our results: only 2 patients with low-grade bAVMs who underwent treatment had poor outcomes (mRS score $\geq 3$ ) at their last follow-up. Importantly, both patients harbored posterior fossa bAVMs, a unique subset of bAVMs that are associated with higher hemorrhage risks as well as poor outcomes regardless of the treatment modality. ${ }^{2,3}$ Curiously, only 1 patient with SM Grade III lesions deteriorated functionally after treatment (SRS) but still had a good outcome. Plausible explanations for this may be the increasing availability of SRS and growing surgical expertise in the management of bAVMs, as well as advances in ancillary disciplines such as neuroanesthesia and neurocritical care. Patients with SM Grade IV and V lesions did not undergo any treatment given the unfavorable risk-benefit profile. Third, no statistically significant difference was detected in the functional outcomes of elderly patients with bAVMs who were treated and those were managed expectantly ( $\mathrm{p}$ $=0.97)$. Additionally, only $1(11 \%)$ of 9 treated patients with unruptured bAVMs had an adverse outcome, which is significantly lower than what was observed in the ARUBA trial. ${ }^{20}$ Fourth, the bAVMs in our series were equally distributed among the supra- and infratentorial compartments, a finding that may have artificially inflated our poor outcomes as posterior fossa bAVMs are inherently dangerous and associated with poorer prognosis., ${ }^{2,3}$ Not surprisingly, the $\mathrm{mRS}$ score at presentation for patients presenting with hemorrhage was significantly higher than in patients who did not rupture (1.9 vs 0.72 , respectively; $p=0.003$ ), emphasizing the fact that functional status of elderly patients is more adversely affected at presentation if their bAVMs rupture. Our subanalysis also reveals that treatment of bAVMs in elderly patients, regardless of the rupture status, does not lead to worse outcomes (preoperative/ postoperative mRS score: ruptured, 1.67/1.67; unruptured, $0.67 / 0.89 ; p=0.58$ ). Should we, then, wait to treat bAVMs only after they rupture and potentially cause permanent deficits or should we use a more aggressive approach and proactively treat bAVMs prior to their rupturing? We believe that in patients who are medically optimized and fit for surgery, proactive and early resection of bAVMs with favorable grade (SM Grade < 4) may lead to better outcomes.

Our analysis has several key limitations. Even though our series represents one of the largest cohorts of elderly patients with bAVMs, the institutional nature of our analysis as well as the relative small sample size may make generalization of our results difficult. Also, the retrospective nature of this study may have introduced sampling bias. We attempted to mitigate this bias by including all patients over the age of 65 years who were diagnosed with pial bAVMs irrespective of other demographic features. Only patients younger than 65 and with nonpial vascular malformations were excluded. Another important limitation stems from the fact that none of our patients underwent preoperative embolization, a useful surgical adjunct that reduces operating time and blood loss. We attempted preoperative embolization in 6 of 11 patients who underwent microsurgical resection but were unsuccessful because difficult vascular architecture, such as vessel tortuosity, prevented safe catheterization. Finally, the omission of the 4 patients who were lost to follow-up may have impacted our outcome analysis. All 4 patients belonged to the observation group ( 2 with ruptured bAVMs and 2 with unruptured bAVMs). Unfortunately, the 4 patients who were lost to follow-up presented to us before the era of electronic 
medical records. While every attempt was made to document the natural progression of these 4 patients, some clinical data were lost during the transfer of hard-copy data to electronic data banks. We believe this to be an isolated incident, and in no way reflects our dedication to collection of meticulous clinical records.

\section{Conclusions}

While most elderly patients with bAVMs present with ICH and may deserve timely treatment, management of elderly patients with unruptured bAVMs remains a challenge due to the absence of treatment guidelines for bAVMs in the elderly. Significant advances in endovascular technology, radiosurgery, and microneurosurgery have made successful treatment of bAVMs in the elderly patients possible. Our experience validates the claim that surgical management of low-grade bAVMs in the elderly is associated with low morbidity; high-grade bAVMs, in contrast, should be managed expectantly.

\section{References}

1. Abecassis IJ, Xu DS, Batjer HH, Bendok BR: Natural history of brain arteriovenous malformations: a systematic review. Neurosurg Focus 37(3):E7, 2014

2. Abla AA, Nelson J, Rutledge WC, Young WL, Kim H, Lawton MT: The natural history of AVM hemorrhage in the posterior fossa: comparison of hematoma volumes and neurological outcomes in patients with ruptured infra- and supratentorial AVMs. Neurosurg Focus 37(3):E6, 2014

3. Arnaout OM, Gross BA, Eddleman CS, Bendok BR, Getch $\mathrm{CC}$, Batjer HH: Posterior fossa arteriovenous malformations. Neurosurg Focus 26:E12, 2009

4. Bendok BR, El Tecle NE, El Ahmadieh TY, Koht A, Gallagher TA, Carroll TJ, et al: Advances and innovations in brain arteriovenous malformation surgery. Neurosurgery 74 (Suppl 1):S60-S73, 2014

5. Bervini D, Morgan MK, Ritson EA, Heller G: Surgery for unruptured arteriovenous malformations of the brain is better than conservative management for selected cases: a prospective cohort study. J Neurosurg 121:878-890, 2014

6. Brown RD Jr, Wiebers DO, Torner JC, O'Fallon WM: Frequency of intracranial hemorrhage as a presenting symptom and subtype analysis: a population-based study of intracranial vascular malformations in Olmsted Country, Minnesota. J Neurosurg 85:29-32, 1996

7. Chibbaro S, Di Rocco F, Makiese O, Mirone G, Marsella M, Lukaszewicz AC, et al: Neurosurgery and elderly: analysis through the years. Neurosurg Rev 34:229-234, 2010

8. Crawford PM, West CR, Chadwick DW, Shaw MD: Arteriovenous malformations of the brain: natural history in unoperated patients. J Neurol Neurosurg Psychiatry 49:1-10, 1986

9. Crowley RW, Ducruet AF, McDougall CG, Albuquerque FC: Endovascular advances for brain arteriovenous malformations. Neurosurgery 74 (Suppl 1):S74-S82, 2014

10. Gross BA, Du R: Diagnosis and treatment of vascular malformations of the brain. Curr Treat Options Neurol 16:279, 2014

11. Gross BA, Du R: Natural history of cerebral arteriovenous malformations: a meta-analysis. J Neurosurg 118:437-443, 2013

12. Harbaugh KS, Harbaugh RE: Arteriovenous malformations in elderly patients. Neurosurgery 35:579-584, 1994

13. Hashimoto H, Iida J, Kawaguchi S, Sakaki T: Clinical fea- tures and management of brain arteriovenous malformations in elderly patients. Acta Neurochir (Wien) 146:1091-1098, 2004

14. Heros RC, Tu YK: Is surgical therapy needed for unruptured arteriovenous malformations? Neurology 37:279-286, 1987

15. Hetts SW, Cooke DL, Nelson J, Gupta N, Fullerton H, Amans MR, et al: Influence of patient age on angioarchitecture of brain arteriovenous malformations. AJNR Am J Neuroradiol 35:1376-1380, 2014

16. Kim H, Al-Shahi Salman R, McCulloch CE, Stapf C, Young WL: Untreated brain arteriovenous malformation: patientlevel meta-analysis of hemorrhage predictors. Neurology 83:590-597, 2014

17. Lanzino G, Fergus AH, Jensen ME, Kongable GL, Kassell NF: Long-term outcome after surgical excision of parenchymal arteriovenous malformations in patients over 60 years of age. Surg Neurol 47:258-263, discussion 263-264, 1997

18. Luessenhop AJ, Rosa L: Cerebral arteriovenous malformations. Indications for and results of surgery, and the role of intravascular techniques. J Neurosurg 60:14-22, 1984

19. Mathers CD, Stevens GA, Boerma T, White RA, Tobias MI: Causes of international increases in older age life expectancy. Lancet 385:540-548, 2015

20. Mohr JP, Parides MK, Stapf C, Moquete E, Moy CS, Overbey JR, et al: Medical management with or without interventional therapy for unruptured brain arteriovenous malformations (ARUBA): a multicentre, non-blinded, randomised trial. Lancet 383:614-621, 2014

21. Orimo H: [Reviewing the definition of elderly.] Nippon Ronen Igakkai Zasshi 43:27-34, 2006 (Jpn)

22. Perret G, Nishioka H: Report on the cooperative study of intracranial aneurysms and subarachnoid hemorrhage. Section VI. Arteriovenous malformations. An analysis of 545 cases of cranio-cerebral arteriovenous malformations and fistulae reported to the cooperative study. J Neurosurg 25:467-490, 1966

23. Rubin BA, Brunswick A, Riina H, Kondziolka D: Advances in radiosurgery for arteriovenous malformations of the brain. Neurosurgery 74 (Suppl 1):S50-S59, 2014

24. Spetzler RF, Martin NA: A proposed grading system for arteriovenous malformations. J Neurosurg 65:476-483, 1986

25. Wang H, Dwyer-Lindgren L, Lofgren KT, Rajaratnam JK, Marcus JR, Levin-Rector A, et al: Age-specific and sexspecific mortality in 187 countries, 1970-2010: a systematic analysis for the Global Burden of Disease Study 2010. Lancet 380:2071-2094, 2012

\section{Disclosures}

The authors report no conflict of interest concerning the materials or methods used in this study or the findings specified in this paper.

\section{Author Contributions}

Conception and design: Pabaney, Malik. Acquisition of data: Pabaney, Reinard. Analysis and interpretation of data: Pabaney, Reinard, Kole. Drafting the article: Pabaney, Reinard. Critically revising the article: all authors. Reviewed submitted version of manuscript: all authors. Approved the final version of the manuscript on behalf of all authors: Pabaney. Statistical analysis: Pabaney. Study supervision: Kole, Seyfried, Malik.

\section{Correspondence}

Aqueel H. Pabaney, K-11, Department of Neurosurgery, Henry Ford Hospital, 2799 W. Grand Blvd., Detroit, MI 48202. email: apabane1@hfhs.org. 